Pawel GIL ${ }^{1}$

\title{
Przejście strugi syntetycznej w strugę turbulentną
}

Struga syntetyczna (ang. synthetic jet) jest rodzajem przepływu generowanym przez ścieżkę wirów pierścieniowych wytwarzanych przez generator strugi syntetycznej. Cechą charakterystyczną urządzenia wytwarzającego strugę syntetyczną jest brak zewnętrznego doprowadzenia płynu. Struga syntetyczna powstaje na skutek cyklicznego ruchu tłoka lub membrany wewnątrz komory, która ma jedną lub wiele dysz w ściance. Struga syntetyczna w bliskiej odległości zbudowana jest z poruszających się wirów pierścieniowych, które dodatkowo zasysają płyn z otoczenia do wewnątrz wiru. Po przekroczeniu pewnej odległości wir rozrasta się zwiększając swoją masę i tracąc spójność przechodzi w przepływ turbulentny. W pracy zaprezentowano wyniki badań eksperymentalnych przejścia strugi syntetycznej w strugę turbulentną.

Słowa kluczowe: struga syntetyczna, struga turbulentna, wir pierścieniowy, generatory przepływu o zerowym wydatku masowym

\section{Wprowadzenie}

Struga syntetyczna jest rodzajem przepływu generowanym przez ścieżkę wirów pierścieniowych wytwarzanych przez generator strugi syntetycznej. Średni wydatek masowy w przekroju dyszy wynosi dokładnie zero, ale spełniając pewną zależność liczb Reynoldsa i Stokesa, uzyskuje się zewnętrzny strumień płynu, tworzący się w pewnej odległości od dyszy. Generator strugi syntetycznej produkuje wówczas serię wirów pierścieniowych (torusów), które zasysają dodatkowy płyn z otoczenia wywołując zewnętrzny przepływ. Generator składa się z trzech głównych elementów: elementu drgającego, komory oraz dyszy. Podczas cyklicznego ruchu membrany powstaje ciąg wirów pierścieniowych („ścieżka wirowa”) poruszających się na zewnątrz dyszy. W pewnej odległości od dyszy ta koherentna struktura załamuje się tworząc przepływ turbulentny.

Na rysunku 1 zaprezentowano dwa schematy strugi syntetycznej, schemat 1a) przedstawia chwilową strugę syntetyczną, widoczne są cyklicznie pojawiające się pierścienie wirowe, które zasysają zewnętrzne powietrze do swojego rdzenia, powodując przepływ zgodnie z niebieską strzałką. Natomiast na schemacie $1 \mathrm{~b}$ zaprezentowano uśrednioną $\mathrm{w}$ czasie strugę syntetyczną, która jest podobna do swobodnej strugi turbulentnej. Sama nazwa struga syntetyczna wzięła

\footnotetext{
${ }^{1}$ Autor do korespondencji/corresponding author: Paweł Gil, Politechnika Rzeszowska, al. Powstańców Warszawy 8, 35-959 Rzeszów, Tel. 17 8651288, e-mail: gilpawel@prz.edu.pl
} 
się od słowa synteza czyli składanie przepływu (strumienia) przez poszczególne wiry.
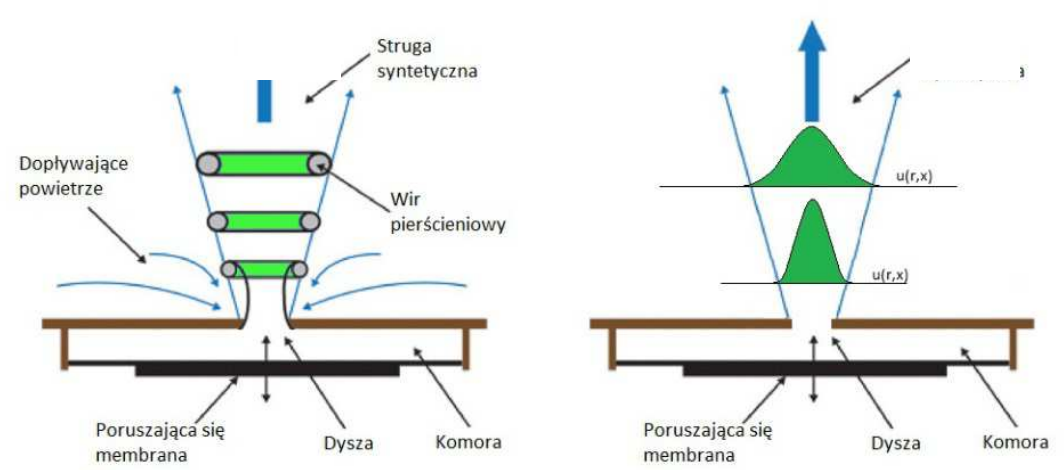

Rys. 1. Struga syntetyczna: a) chwilowa, b) uśredniona w czasie

Fig. 1. Synthetic jet: a) instantaneous, b) time-averaged

Kryterium powstawania strugi syntetycznej jest koniecznym warunkiem powstania przepływu. Kilka wyraźnych punktów występowania i niewystępowania strugi syntetycznej można znaleźć w literaturze $[4,11,14,16,17,20]$ Holman i in. [5] wykonali badania eksperymentalne i sformułowali kryterium powstawania strugi syntetycznej w postaci:

$$
\frac{R e}{S t k^{2}} \geq K
$$

gdzie: Stk - liczba Stokesa, Re - liczba Reynoldsa strugi syntetycznej (obliczanej z prędkości uśrednionej czasowo i przestrzennie podczas cyklu wytłaczania), K to pewna stała zależna od geometrii dyszy. Dla dysz osiowosymetrycznych (okrągłych) $\mathrm{K}=0,16$.

Smith i Swift [15] porównywali strugę syntetyczną ze strugą swobodną dla tych samych liczb Reynoldsa, z czego wynikało, że struga syntetyczna w bliskiej odległości jest zdominowana przez wiry pierścieniowe, które zasysają dodatkowy płyn do środka wiru. W dalekiej odległości struga syntetyczna wykazuje duże podobieństwo do strugi ciągłej.

Celem pracy jest wykonanie pomiarów eksperymentalnych profili promieniowych i osiowych prędkości strugi syntetycznej i wykazanie podobieństwa do strugi swobodnej. Dodatkowo dokonano pomiaru prędkości chwilowych i wyjaśniono zasadę działania strugi syntetycznej. Badany problem jest istotny ze względu na kąt rozchodzenia się strugi syntetycznej, który wynosi około $10,5^{\circ}$. Zaprezentowane wyniki mogą służyć optymalizacji wykorzystania generatorów strugi syntetycznej do aplikacji rozpraszania ciepła. 


\section{Stanowisko pomiarowe}

Komora generatora strugi syntetycznej zbudowana do celów badawczych składa się z przetwornika elektroakustycznego (głośnika) o średnicy $160 \mathrm{~mm}$, jako elementu wykonawczego, zamontowanego w wyfrezowanej płycie ze szkła organicznego mającego otwór o średnicy $150 \mathrm{~mm}$. Płyta zamykająca komorę posiada cylindryczną dyszę o średnicy d oraz długości t. W prezentowanych wynikach wykorzystywano średnicę dyszy $\mathrm{d}=15 \mathrm{~mm}$ oraz stałą długość dyszy $\mathrm{t}=5 \mathrm{~mm}$. Płyty zamykające są wymienne tak, aby można było zastosować dyszę o różnych średnicach i długościach. Objętość komory $\mathrm{V}$ jest regulowana. Polega to na dodaniu lub odjęciu płyt pośrednich pomiędzy przetwornikiem elektroakustycznym, a płytą zamykającą. Głębokość komory była stała i wynosiła $\mathrm{H}=40$ $\mathrm{mm}$.

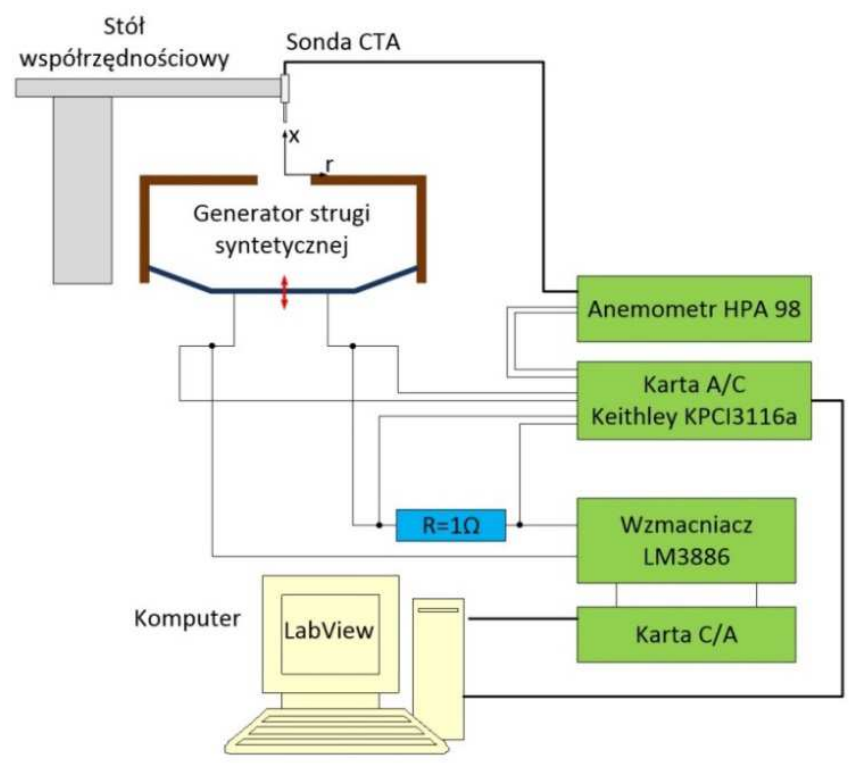

Rys. 2. Schemat stanowiska pomiarowego

Fig. 2. Scheme of measuring position

Generator strugi syntetycznej został zasilony wzmacniaczem mocy zbudowanym na podstawie układu scalonego LM3886 zasilanego symetrycznie. Wzmacniacz został podłączony do wyjścia analogowego karty dźwiękowej posiadającej przetwornik cyfrowo-analogowy (DAC) 16-bitowy. Częstotliwość próbkowania wynosiła $48 \mathrm{kHz}$. Podczas wykonywania badań częstotliwość wzbudzenia membrany przetwornika elektroakustycznego $\mathrm{f}$ zmieniała się w zakresie 5-400 Hz. Zastosowano 8-omowy głośnik STX 6,5 200. Przetwornik elektroakustyczny był zasilany napięciem przemiennym o przebiegu sinusoidalnym, 
ze wzmacniacza mocy o wartości skutecznej napięcia stałej dla wszystkich pomiarów $\mathrm{U}=3 \mathrm{~V}$.

Do pomiaru prędkości powietrza zastosowano termoanemometr stałotemperaturowy jednowłóknowy HPA 98 o średnicy włókna $5 \mu \mathrm{m}$ oraz długości włókna $1 \mathrm{~mm}$. Włókno zostało wykonane z wolframu. Sygnał napięciowy był rejestrowany za pomocą karty pomiarowej KPCI-3116A firmy Keithley (rys. 2). Częstotliwość próbkowania dobierano automatycznie jako trzydziestodwukrotność częstotliwości pracy generatora strugi syntetycznej. Termoanemometr został przewzorcowany w tunelu aerodynamicznym w zakresie $0,7-30 \mathrm{~m} / \mathrm{s}$. Punkty wzorcowe aproksymowano wielomianem czwartego-stopnia. Rozszerzona niepewność pomiaru $(2 \sigma, 95 \%$ ufność) prędkości była mniejsza o $4 \%$. Pomiary wykonywano $\mathrm{w}$ klimatyzowanym laboratorium o temperaturze $\mathrm{T}=$ $21 \pm 1^{\circ} \mathrm{C}$. Wilgotność względną oraz temperaturę powietrza mierzono higrometrem Testo 6681. Wilgotność względna $\mathrm{w}$ pomieszczeniu podczas pomiarów wynosiła $\varphi=50 \pm 10 \%$. Płynem generatora strugi syntetycznej było powietrze atmosferyczne. Dla każdego punktu pomiarowego dokonywano pomiaru 50 cykli. Kierunek prędkości nie może być określony z pomiarów termoanemometru. $\mathrm{Na}$ podstawie zarejestrowanego modułu prędkości dokonano inwersji połówki sinusoidy odpowiadającej za cykl zasysania powietrza do komory. Wykorzystano w tym celu procedurę opisaną w pracy [12].

\section{Wyniki badań eksperymentalnych}

W celu porównania strugi syntetycznej ze strugą turbulentną zarejestrowano średnią prędkość powietrza wzdłuż osi dyszy (na kierunku x). Struga syntetyczna w bliskiej odległości zdominowana jest przez cykliczne pierścienie wirowe, które wraz ze przebytą drogą zwiększają swoją masę [9] i rozpadają się tworząc przepływ turbulentny. Mallinson i inni [10] wykazali podobieństwo profilu strugi syntetycznej do strugi turbulentnej po dystansie 10d. Cater i inni [1] podają wartość $15 \mathrm{~d}$ opartą na średniej prędkości. Chaudharii i inni [2] podają że przepływ turbulentny zaczyna się po dystansie $7 \mathrm{~d}$, gdzie d to średnica dyszy. Wyniki eksperymentalne pomiaru prędkości strugi syntetycznej w funkcji odległości x (rys. 3) ukazują, że powyżej bezwymiarowej odległości $\mathrm{x} / \mathrm{d} \approx 9$ przepływ zanika w tempie proporcjonalnym do $1 / \mathrm{x}$ podobnie jak swobodna struga turbulentna [19]. Na wykresie (rys. 3) można zauważyć lokalne maksimum prędkości występujące $\mathrm{w}$ odległości około $\mathrm{x} / \mathrm{d} \approx 3$. Powyżej tej odległości nie występuje oddziaływanie cyklu zasysania powietrza na prędkość chwilową. Struga syntetyczna w bliskiej odległości, począwszy od $\mathrm{x} / \mathrm{d}=0$ posiada prędkość średnią wynoszącą zero, wynika to z cyklicznego zasysania i wytłaczania powietrza przez dyszę. Na rysunku 4 przedstawiono prędkość chwilową strugi syntetycznej dla kilku reprezentatywnych odległości od dyszy x/d. Prędkość powietrza została zarejestrowana synchronicznie względem sygnału sinusoidalnego zasilającego generator strugi syntetycznej i uśredniona z 20 okresów T. 


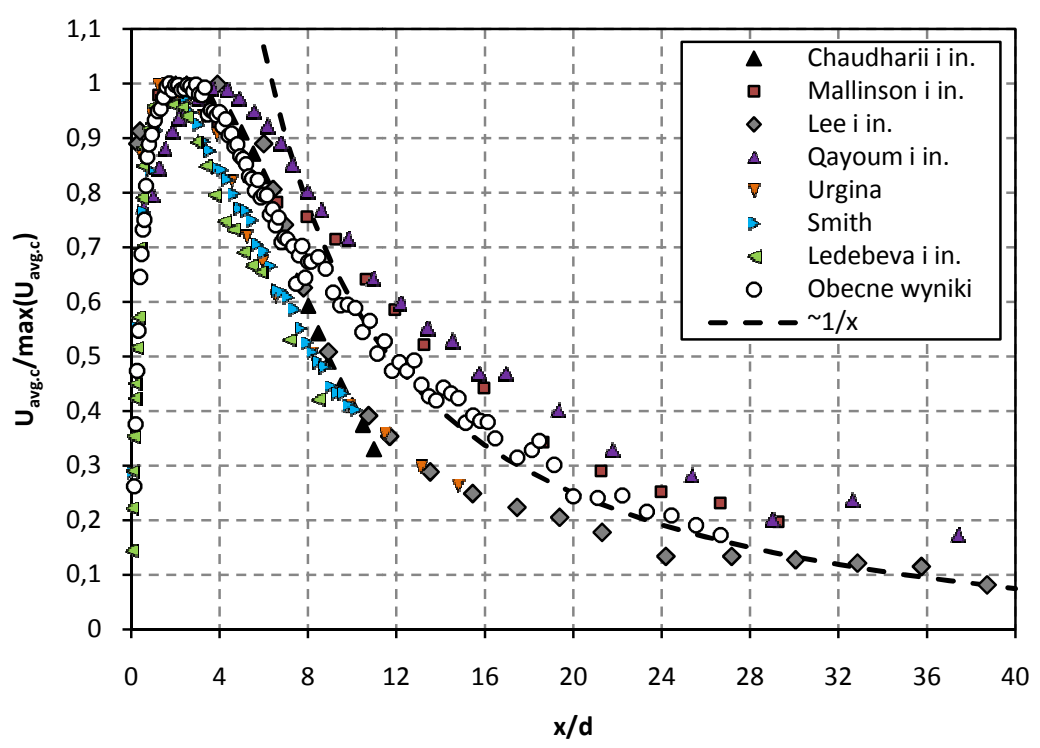

Rys. 3. Bezwymiarowa prędkość strugi syntetycznej w osi dyszy uśredniona czasowo, w funkcji bezwymiarowej odległości: $\mathrm{Re}=23280 ; \mathrm{Stk}=53 ; \mathrm{t} / \mathrm{d}=1,33 ; \mathrm{H} / \mathrm{d}=2,67$

Fig. 3. Dimensionless time-averaged velocity of synthetic jet centerline as a function of dimensionless distance: $\operatorname{Re}=23280, \mathrm{Stk}=53, \mathrm{t} / \mathrm{d}=1.33, \mathrm{H} / \mathrm{d}=2.67$

Na wykresie (rys. 4) można zaobserwować, że w odległości x/d $<3$ prędkość chwilowa w osi dyszy ma przebieg sinusoidalny o połówce dodatniej odpowiadającej za cykl wytłaczania płynu oraz połówce ujemnej odpowiadającej za zasysanie płynu do komory generatora strugi syntetycznej. Wraz ze zwiększaniem odległości $\mathrm{x} / \mathrm{d}$ prędkość $\mathrm{w}$ cyklu zasysania maleje do zera, a tym samym średnia prędkość rośnie. Maksima w przebiegach czasowych prędkości odpowiadają czasowi przybycia wiru pierścieniowego do punktu pomiarowego w zadanej odległości $\mathrm{x} / \mathrm{d}$.

Struga syntetyczna po pewnym dystansie zachowuje się podobnie jak struga swobodna turbulentna [16]. Dokonując pomiaru prędkości średniej strugi syntetycznej w przekrojach równoległych do powierzchni dyszy, otrzymano następujące wyniki zaprezentowane na (rys. 5). Wraz z przemieszczaniem się wiru, następuje zwiększenie jego średnicy [22], a tym samym zwiększanie się szerokości profilu prędkości wraz ze wzrostem płaszczyzny pomiaru $\mathrm{x} / \mathrm{d}$. Pomiary profili prędkości dokonano włącznie do odległości $\mathrm{x} / \mathrm{d}=15$. W celu porównania profili strugi syntetycznej oraz strugi swobodnej turbulentnej zastosowano procedurę bezwymiarową opisaną $\mathrm{w}$ [6][3]. W tym celu poszukuje się wirtualny początek $\mathrm{x}_{0}$ rdzenia (rys. 6 i 7 ). 


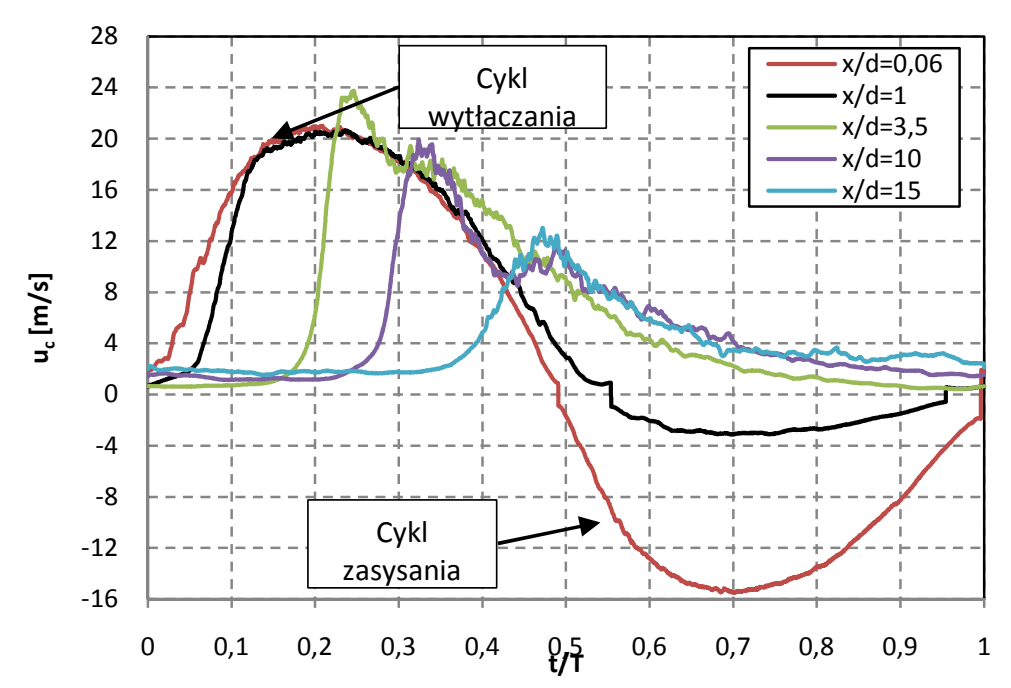

Rys. 4. Prędkość chwilowa strugi syntetycznej w osi dyszy dla różnych odległości od dyszy: $\mathrm{x} / \mathrm{d}=0,06 \div 15 ; \mathrm{Re}=23280 ; \mathrm{Stk}=53 ; \mathrm{t} / \mathrm{d}=1,33 ; \mathrm{H} / \mathrm{d}=2,67$

Fig. 4. Instantaneous velocity of synthetic jet centerline for various dimensionless distances: $\mathrm{x} / \mathrm{d}=0,06 \div 15 ; \mathrm{Re}=23280 ; \mathrm{Stk}=53 ; \mathrm{t} / \mathrm{d}=1,33 ; \mathrm{H} / \mathrm{d}=2,67$

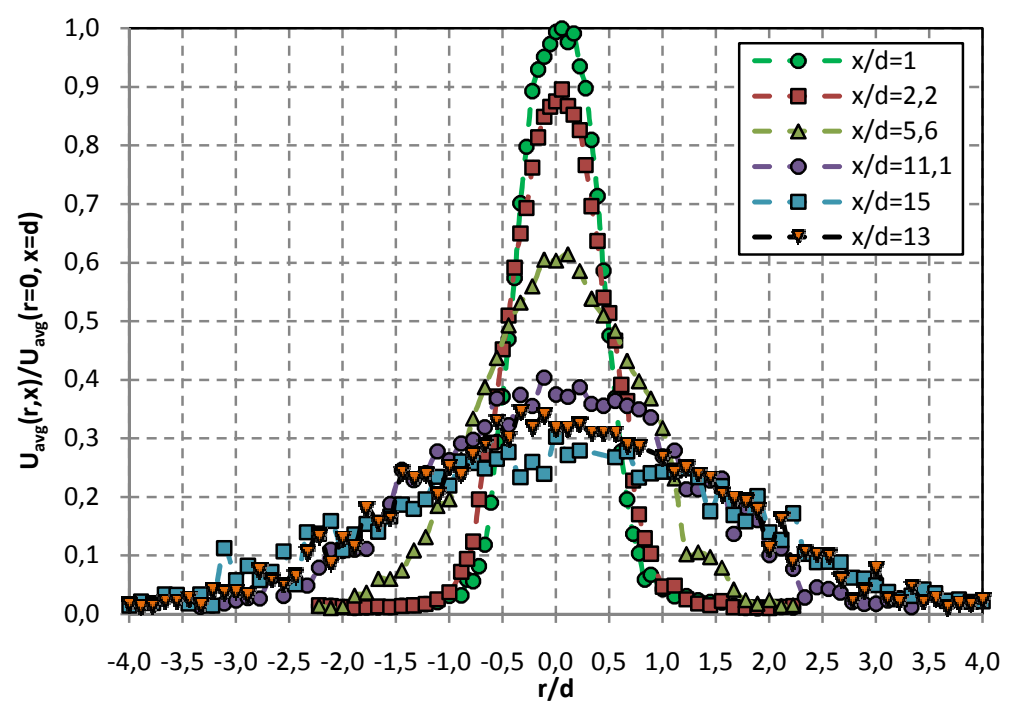

Rys. 5. Profile promieniowe prędkości czasowo średniej strugi syntetycznej: Re $=13920 ;$ Stk $=42 ; \mathrm{t} / \mathrm{d}=0,56 ; \mathrm{H} / \mathrm{d}=4,44$

Fig. 5. Radial profiles of time-averaged velocity of synthetic jet: $\operatorname{Re}=13920$, $\mathrm{Stk}=42, \mathrm{t} / \mathrm{d}=0.56, \mathrm{H} / \mathrm{d}=4.44$ 


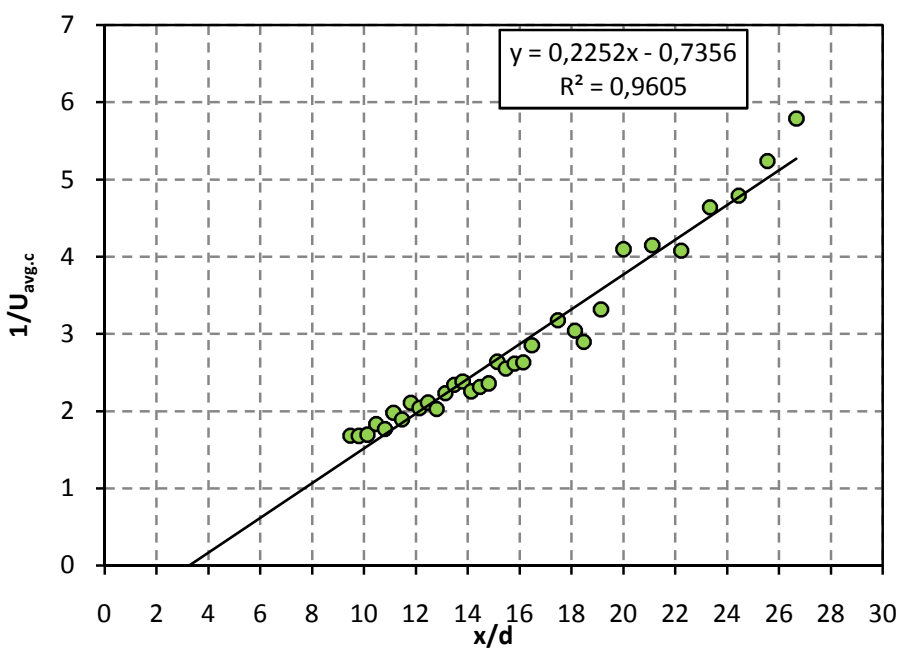

Rys. 6. Odwrotność prędkości średniej strugi syntetycznej powyżej odległości $\mathrm{x} / \mathrm{d}>9$, widoczny jest wirtualny początek $\mathrm{x}_{0}=3,3 \mathrm{~d} ; \quad(\mathrm{Re}=23280 ; \mathrm{Stk}=$ $53 ; \mathrm{t} / \mathrm{d}=1,33 ; \mathrm{H} / \mathrm{d}=2,67$ )

Fig. 6. The inverse of the average velocity of synthetic jet over a distance $\mathrm{x} / \mathrm{d}>9$; it is visible the virtual origin $\mathrm{x}_{0}=3.3 \mathrm{~d}(\operatorname{Re}=23280, \mathrm{Stk}=53, \mathrm{t} / \mathrm{d}=$ $1.33, \mathrm{H} / \mathrm{d}=2.67$ )

W aktualnych badaniach eksperymentalnych wirtualny początek zaczyna się w odległości 3,3 d. Chaudhari i inni [2] dla strugi syntetycznej znaleźli wirtualny początek w odległości 4d, podobnie jak Hussein i inni [6] dla strugi swobodnej turbulentnej. Prędkość bezwymiarowa wyznaczana jest przez podzielenie prędkości średniej $\mathrm{U}_{\mathrm{avg}}(\mathrm{r}, \mathrm{x})$ w punkcie $(\mathrm{r}, \mathrm{x})$ przez prędkość średnią $\mathrm{W}$ osi symetrii dyszy $\mathrm{U}_{\text {avg.c }} \mathrm{W}$ punkcie $(\mathrm{r}=0, \mathrm{x})$. Bezwymiarowa współrzędna promieniowa wyznaczana jest przez podzielenie jej przez współrzędną osiową pomniejszoną o wirtualny początek $\mathrm{r} /\left(\mathrm{x}-\mathrm{x}_{0}\right)$.

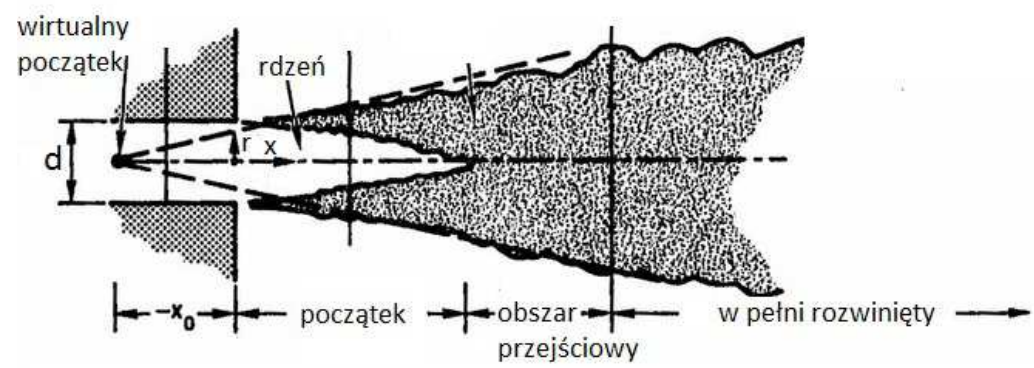

Rys. 7. Osiowosymetryczna struga turbulentna - widoczny jest wirtualny początek w odległości $\mathrm{x}_{0}$ (opracowano na podstawie [6])

Fig. 7. Axisymmetric turbulent jet, it is visible the origin distance of $x_{0}$; prepared based on the [6] 


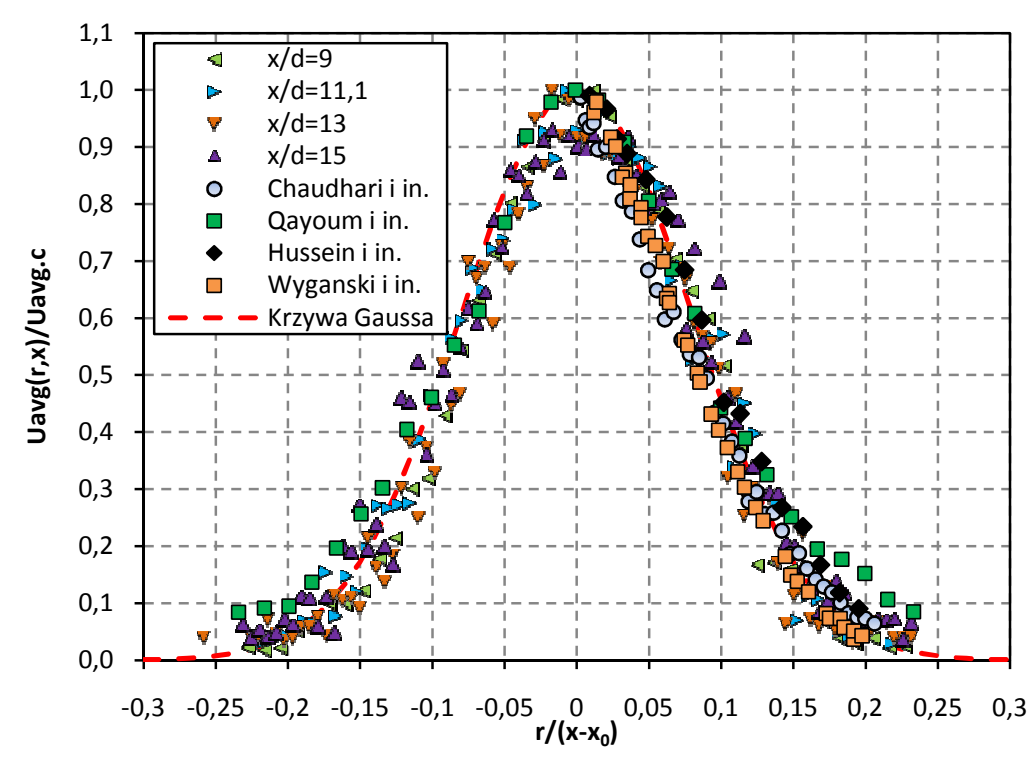

Rys. 8. Porównanie bezwymiarowych profili średniej prędkości powietrza dla bezwymiarowej odległości $\mathrm{x} / \mathrm{d}=9 \div 15(\mathrm{Re}=13920, \mathrm{Stk}=42, \mathrm{t} / \mathrm{d}=0.56, \mathrm{H} / \mathrm{d}=$ 4.44) z wynikami podanymi w literaturze. Struga syntetyczna: Chaudhari i in. [2] oraz Qayoum i in. [13], x/d =6. Turbulentna struga swobodna: Hussein i in. [6] oraz Wyganski i Fiedler [19], x/d = 30

Fig. 8. Comparison of the dimensionless profiles of average velocity of air for the dimensionless distance $\mathrm{x} / \mathrm{d}=9 \div 15(\operatorname{Re}=13920, \mathrm{Stk}=42, \mathrm{t} / \mathrm{d}=0.56, \mathrm{H} / \mathrm{d}=4.44)$ with the results reported in the literature. Synthetic jet: Chaudhari et al. [2], and Qayoum et al. [13], $\mathrm{x} / \mathrm{d}=6$. Turbulent jet: Hussein et al. [6], and Wyganski and Fiedler [19], $\mathrm{x} / \mathrm{d}=30$

\section{Podsumowanie}

W teksie zaprezentowano wyniki badań eksperymentalnych pomiaru prędkości osiowej oraz profili prędkości strugi syntetycznej oraz porównano uzyskane wyniki z profilami swobodnej strugi turbulentnej. Wyniki pomiaru ukazują zaskakujące podobieństwo uśrednionej czasowo strugi syntetycznej ze strugą turbulentną, począwszy od odległości $\mathrm{x} / \mathrm{d}=9$. W bliskiej odległości występują znaczne różnice pomiędzy strugą syntetyczną i turbulentną:

- Prędkość średnia w odległości $\mathrm{x} / \mathrm{d}=0$ dla strugi syntetycznej wynosi dokładnie zero, natomiast dla strugi turbulentnej posiada wartość maksymalną.

- Odmienny jest mechanizm tworzenia przepływu. Dla strugi syntetycznej, której średni wydatek masowy w przekroju dyszy wynosi zero, przepływ generowany jest wirami pierścieniowymi zasysającymi dodatkowe zewnętrzne powietrze do wnętrza wiru, generując niezerowy wydatek. Struga turbulentna natomiast powstaje na skutek różnicy ciśnienia. 


\section{Literatura}

[1] Cater J.E., Soria J.: The evolution of round zero-net-mass-flux jets, J. Fluid Mech., 472 (2002) 167-200.

[2] Chaudhari M., Verma G., Puranik B., Agrawal A.: Frequency response of a synthetic jet cavity, Exp. Thermal Fluid Sci., 33 (2009) 439-448.

[3] Frohnapfel B.: Multi-point similarity of the axisymmetric turbulent far jet and its implication for the POD, Master Thesis, Chalmers University of Technology, Goteborg 2003.

[4] Gil P., Strzelczyk P.: Kryterium powstawania strugi syntetycznej, ZN PRz Mechanika, 86 (2014) 517-525.

[5] Holman R., Utturkar Y., Mittal R., Smith B.L., Cattafesta L.: Formation criterion for synthetic jets, The American Inst. Aeronautics Astronautics, 43 (2005) 21102116.

[6] Hussein H., Capp S., George W.: Velocity measurements in high Reynolds number. Momentum-conserving, axisymmetric, turbulent jet, J. Fluid Mech., 258 (1994) 31-75.

[7] Ledebeva I.V., Grushin A.E.: Amplitude and frequency characteristic of acoustic jets, Acoustical Physics, 49 (2003) 300-304.

[8] Lee C., Timchenko V., Yeoh G.H., Reizes J.A.: Effect of the variable properties on heat transfer in micro-channel with synthetic jet, $9^{\text {th }}$ Australasian Heat and Mass Transfer Conference, Melbourne 2011.

[9] Liang Shao-Yo: Mass of air cannon vortex. International School Bangkok, ISB Journal of Physics (http://www.isjos.org) Bangkok 2007.

[10] Mallinson S.G., Reizes J.A., Hong G., Westbury P.S.: Analysis of hot-wire anemometry data obtained in a synthetic jet flow, Exp. Thermal Fluid Sci., 28 (2004) 265-272.

[11] Milanovic I.M., Zaman K.B.M.Q.: Synthetic Jets in Crossflow, AIAA Journal, 43 (2005) 929-940.

[12] Pavlova A., Amitay M.: Electronic cooling with synthetic jet impingement, J. Heat Transfer, 128 (2006), 897-907.

[13] Qayoum A., Gupta V., Panigrahi P.K., Muralidhar K.: Influence of amplitude and frequency modulation on flow created by a synthetic jet actuator, Sensors Actuators, A 162 (2010) 36-50.

[14] Shuster J.M., Smith D.R.: A study of the formation and scaling of a synthetic jet. Reno, NV: AIAA Paper 2004-0090.

[15] Smith B., Swift G.: A comparison between synthetic jets and continuous jets. Experiments in Fluids 34 (2003) 467-472

[16] Smith D.R.: A study of the formation and scaling of synthetic jet, Final Report F49620-01-1-0301, University of Wyoming. 2005

[17] Timchenko V., Reizes J., Leonardi E., de Vahl Davis G.: A criterion for the formation of micro synthetic jets, ASME Int. Mech. Eng. Congress Exposition (IMECE2004), Anaheim 2004, California, pp. 197-203. 
[18] Urgina S.: Experimental analysis and analytical modeling of synthetic jet-cross flow interactions, Doctor of Philosophy dissertation, University of Maryland 2007.

[19] Wygnanski I., Fiedler H., Some measurements in self-preserving jet, J. Fluid Mechanics 38 (1969) 577-612.

[20] Zhou J., Tang H., Zhong S.: Vortex roll-up criterion for synthetic jets, AIAA Journal, 47 (2009) 1252-1262.

\section{TRANSITION OF SYNTHETIC JET INTO TURBULENT JET}

\section{S u m m a r y}

Synthetic jet is a type of flow generated by the path of the ring-shaped vortex produced by a generator of synthetic jet. A characteristic feature of the synthetic jet generator is a lack of external supply of fluid. Synthetic jet arises from the cyclic movement of the piston or diaphragm inside the chamber, that has one or more nozzles in the wall. Synthetic jet is made up of moving ringshaped vortexes that also suck fluid into the inside of the vortex from the environment. Beyond a certain distance the vortex grows increasing its mass and losing stability, and then it transfers into a turbulent flow. In this paper the results of the experimental research of synthetic jet's transferring into turbulent jet is presented.

Keywords: synthetic jet, turbulent jet, ring-shaped vortex, zero-net-mass-flux generator

DOI: $10.7862 / \mathrm{rm} .2016 .3$

Otrzymano/received: $19.10 .2015 \mathrm{r}$.

Zaakceptowano/accepted: 21.03.2016 r. 